This item was submitted to Loughborough's Research Repository by the author.

Items in Figshare are protected by copyright, with all rights reserved, unless otherwise indicated.

\title{
Drilling in carbon/epoxy composites: experimental investigations and finite element implementation
}

PLEASE CITE THE PUBLISHED VERSION

http://dx.doi.org/10.1016/j.compositesa.2012.11.020

PUBLISHER

(C) Elsevier

VERSION

AM (Accepted Manuscript)

LICENCE

CC BY-NC-ND 4.0

\section{REPOSITORY RECORD}

Phadnis, Vaibhav A., Farrukh Makhdum, Anish Roy, and Vadim V. Silberschmidt. 2019. "Drilling in Carbon/epoxy Composites: Experimental Investigations and Finite Element Implementation”. figshare. https://hdl.handle.net/2134/11689. 


\title{
Drilling in carbon/epoxy composites: experimental
}

\section{investigations and finite element implementation}

\author{
Vaibhav A. Phadnis, Farrukh Makhdum, Anish Roy, Vadim V. Silberschmidt* \\ Loughborough University, UK \\ *Corresponding author, Email: v.silberschmidt@lboro.ac.uk \\ Phone: $+44(0) 1509 / 227504$, Fax: $+44(0) 1509 / 227648$
}

\begin{abstract}
Drilling is one of the principal machining operations used to facilitate assembly of components made from fibre reinforced polymer composites (FRPs). Drilling carbon fibre reinforced plastics (CFRPs) is cumbersome due to high structural stiffness of the composite and low thermal conductivity of the epoxy material. Additionally resin-rich areas between neighbouring plies in a laminate are prone to delamination that compromises structural integrity of the component. Appropriate selection of drilling parameters is believed to mitigate damage in CFRPs. In this context, we study the effect of cutting parameters on drilling thrust force and torque during the machining process both experimentally and numerically. A unique three-dimensional (3D) finite element model of drilling in a composite laminate is developed. Cohesive zone elements are used to simulate delamination damage between the individual plies of the composite. The model accounts for the complex kinematics at the drillworkpiece interface. Experimental quantification of drilling induced damage is performed with the aid of X-ray micro-tomography. The developed numerical model is shown to agree reasonably with the experiments. The model is used to predict favourable drilling parameters in carbon/epoxy composites.
\end{abstract}

Keywords: Carbon-epoxy composites, B. Drilling induced delamination, C. Finite element analysis, D. Image processing 


\section{Introduction}

Composite materials offer excellent strength-to-weight ratio, damage tolerance, fatigue and corrosion resistance, which make them good candidates for replacement of conventional materials for structural applications. As a result, advanced composite materials make about $50 \%$ of the structural weight of Boeing 787and Airbus A350XWB [1]. Generally, parts made of composites are produced to a near-net shape, but additional machining operations are often required to facilitate component assembly. For example, joining of composite components to a structure often requires manufacturing holes in them in order to place bolts or rivets. To manufacture these holes, drilling is a commonly used machining process. In it a rigid tool, typically a twist drill, cuts out the required area of the composite workpiece. During this process the tool encounters alternatively matrix and reinforcement materials, of which response to machining can be completely different. The process implies destruction of fibre continuity with generation of large stress concentration in the material and delamination at the hole entry and exit [2-7]. The damage caused can significantly reduce the fatigue strength of the component, thus degrading the long-term performance of composite laminates [8-9]. Previous studies have shown that machining fibre-reinforced polymer (FRP) composites materials differs significantly in many aspects from machining conventional metals and alloys primarily due to the underlying heterogeneity and anisotropy of FRP materials [2-9].

In the literature, experimental, analytical and numerical modelling techniques have been used to study cutting mechanisms in FRP machining; excellent reviews on composite machining can be found in [5-6, 10-14]. Experimental findings, though useful, provide limited information on underlying mechanics of composite deformation and damage propagation. Recently, numerical modelling has been used as a tool for a better understanding of machining of these composites. These studies typically focus on 2D models of cutting [1517], which cannot account realistically for actual complex three-dimensional shape of cutting tool and the kinematics of the drilling process. However, advances in computational power 
led to the development of modelling tools and numerical strategies, which cover a wide range of temporal and geometrical length scales, as well as higher dimensionality.

This paper deals with drilling of CFRP composites and is arranged as follows: In Section 2, a comprehensive overview of drilling experiments and an X $\mu \mathrm{CT}$ scanning procedure is provided followed by discussion of experimental results. In Section 3, a detailed strategy used to develop a 3D finite-element model of drilling in a CFRP laminate is discussed. In Section 4, we present the results of finite-element simulations along with an optimisation study focussed on determination of an appropriate combination of machining parameters in order to mitigate drilling-induced damage.

\section{Drilling experiments}

\subsection{Machine setup}

The drilling experiments were conducted on a Harrison M-300 lathe machine with $2.24 \mathrm{~kW}$ spindle power and a maximum speed of $2500 \mathrm{rpm}$. A Jobber carbide TiN-coated twist drill bit with diameter $3 \mathrm{~mm}$ was mounted in its three-jaw universal chuck. The experimental setup and drill bit topology is shown in Figure 1.

A dynamometer was placed on the cross-slide of the lathe using an angle plate. The two-channel Kistler ${ }^{\text {TM }}$ (Model number $9271 \mathrm{~A}$ ) dynamometer was used to acquire thrust force and torque data. The obtained signal was converted and transmitted to the computer via analogue-digital converter (digital oscilloscope Piscoscope ${ }^{\mathrm{TM}}$ ). Matlab ${ }^{\mathrm{TM}}$ [18] was used to process the measured data.

\subsection{Material specification}

The composite specimens were made of T300/LTM45-EL carbon/epoxy unidirectional (UD) laminate with a ply thickness of in a cross-ply lay-up $\left[0_{4} / 90_{8} / 0_{4}\right]$. This composite system was selected mainly because its mechanical property database is available at Loughborough University [19] and LTM45-EL epoxy can be easily cured at low temperature. The 
mechanical properties of a UD T300/LTM45-EL ply are listed in Table 1. A dedicated fixture system was manufactured to attach the workpiece to the dynamometer. The carbon/epoxy specimen was held on the backing plate with a central hole of $16 \mathrm{~mm}$ diameter which coincides with the drilling axis. The CFRP specimen is attached to the backing plate with the help of clamps in order to reduce the exit delamination (refer Figure 1).

\subsection{Machining parameters and results}

The experiments were conducted at $2500 \mathrm{rpm}$ at three different feed rates given in Table 2 . The obtained thrust force and torque for different combinations of feeds are shown in Table 3. The latter were chosen according to industry standards in order to examine their effect on entry and exit delamination at constant cutting speed. Each experiment was repeated three times to ensure repeatability of results.

\subsection{Delamination analysis}

Delamination is one of the principal damage modes observed after drilling composite materials $[5-6,14,20-24]$ and it can often be a limiting factor in the use of laminates for structural applications. Delamination not only reduces component assembly tolerances and bearing strength, but also long term performance under fatigue loads.

In order to assess the level of delamination damage around drilled holes, a onedimensional delamination factor which is defined as the ratio of the damaged (delaminated) area to a nominal area around the drilled hole, is used in our analysis. The delamination factor was evaluated using digital-image processing technique and a true damage area was measured in terms of pixelated region.

\subsection{Damage characterisation with X-ray tomography}

Measurements with X-ray micro computed tomography $(\mathrm{X} \mu \mathrm{CT})$ were carried out using $\mathrm{X}$-tech system ${ }^{\mathrm{TM}} \mathrm{XTH}-160$ machine. Each sample was exposed to radiation and rotated through 
$360^{\circ}$ to capture the images for $3 \mathrm{D}$ construction. The X-ray voltage and current were set as 80 $\mathrm{kV}$ and $75 \mathrm{~mA}$ respectively. X-rays were diverged conically from the source and received by the receiver after encountering the specimen. The scanning parameters are given in Table 4. The specimens of $10 \mathrm{~mm}$ width were exposed at a distance of $12 \mathrm{~mm}$ to the source. The source has a spot size of $3 \mu \mathrm{m}$. Transmission X-ray images were acquired from 64 rotational views for $360^{\circ}$ of rotations. Each sample was scanned for 150 minutes with 2.34 second per projection. Software VG Studio ${ }^{\mathrm{TM}} 2.0$ was used for reconstruction and post processing. The maximum possible resolution was $7.3 \mu \mathrm{m}$. To achieve the damage cloud at entry and exit for evaluation of delamination, an iso-transparent reconstruction method was used.

\subsection{Delamination quantification}

The CT scan images of drilled holes obtained with the X $\mu$ CT system were used as an input to the code developed in Matlab ${ }^{\mathrm{TM}}[18]$ to quantify the extent of delamination at the entry and exit. The following procedure was employed to obtain the final image used to quantify delamination.

A digitalised volume of the drilled CFRP workpiece volume was cut in a way to ensure that the bounded envelope covered all quantifiable delamination zones. For the entire analysis, 2D slices of the laminae provided input images to quantify delamination-affected zone at drill entry and exit (refer Figure 2). This envelope was held constant for all three feed rates in the study of the effect of feed rate on the extent of delamination. These images were considered as matrices where columns and rows identify points of the image, with the values corresponding to luminosity of these points. Using a discrete process, a rectangular grid was employed for the image where pixel cells were identified by co-ordinates with the origin at the upper left corner of the image. The post-drilling images obtained were used as an input for image processing to quantify the delamination. The details of capability of the CT scanner and the steps in determining the delamination factor are discussed below. The numerical code written in Matlab filtered dynamic noise in the image and digitised the delamination 
zone into pixels. Contrast enhancement was facilitated to distinguish the sharp edges based on the optimal upper threshold value of 200 and the lower threshold value of 32 , wherein the bound range varies from 0 to 256 for an RGB image.

The output obtained with this code was a black and white image, where black pixels corresponded to the undamaged area, while white pixels indicated the damaged area (Figure 9 - row 1 and 3). The distribution of black and white pixels was measured using the image histogram function. The black pixels representing drilled hole area $\left(N_{B H}\right)$, which is not necessarily a circular area, were eliminated from the calculation (refer Figure 2). A delamination factor $D$ introduced here differs from the traditional definition of delamination factor in composites. In prior studies $[22,23]$ this has been defined as the ratio of a the maximum diameter of the circle enclosing the damaged/delaminated zone and the drilled hole diameter. This approach has inherent disadvantages as it also counts undamaged areas in non-circular delamination profiles. In our study, we define $D$ as

$$
D=\frac{\text { Damaged area }}{\text { Total intact area }}=\frac{N_{W}}{N_{W}+N_{B}-N_{B H}} .
$$

where $N_{W}$ and $N_{B}$ are the numbers of white and black pixels (refer Figure 3). This definition of $D$ is a physically accurate representation of damage in the studied envelope.

\section{Finite element model of drilling in carbon/epoxy composites}

In case of composite laminates, to increase drilling efficiency along with damage mitigation, it is imperative to understand the effect of machining parameters on CFRP. Various experimental studies were carried out in the past $[4,7,14,20-24]$ to optimise the machining parameters in order to obtain better performance in drilling of CFRP composites. Several analytical models [25-28] were also developed to determine the critical thrust force and torque for drilling of composites; however, those empirical formulae were solely based 
on a geometric configuration of tool-workpiece system, and are not suitable for thick composite laminates and general process conditions.

Finite-element (FE) techniques offer a framework to develop a numerical model, which could reasonably describe the drilling process in CFRP composites and predict the corresponding levels of thrust force and torque, as well as delamination failure within a relatively reasonable computational time. When constructing and meshing the FE model, it is important to follow experimental conditions as closely as possible; though in some cases it is also necessary to make some assumptions to simplify the model in order to speed up the analysis or, even to make it feasible for available computational resources. An appropriate balance between reducing the computation time and increasing precision of results can be achieved by an adaptive choice of factors such as model complexity, mesh size and shape. Once validated, FE models are convenient and efficient tools to use for engineering tasks.

\subsection{Material modelling}

In this paper, a user-defined 3D damage model (VUMAT) with solid elements was developed and implemented into the finite-element code Abaqus/explicit [29] to predict the character and extent of damage through the laminate thickness. Interface cohesive elements were inserted between the plies of the modelled laminate to simulate delamination. The general contact algorithm in Abaqus/explicit was used to simulate contact conditions between the twist drill and the composite laminate, and between the layers by defining appropriate contact-pair properties. An element deletion approach [30] was used to represent the hole-making process based on initiation and evolution of damage in the meshed CFRP elements. The results of numerical simulations were evaluated using comparison with experimental data.

\subsection{Damage initiation}

Damage modelling in the meso-scale, typically starts with homogenized ply properties with interplay behaviour and information about the laminate lay-up. Numerical 
models are used to predict homogenised composite response until fracture of structural components. This, a ply-by-ply method to model the progressive failure in composites provides several advantages. Firstly, full 3D stress states can be considered, as opposed to simulations based on shell elements for the composite plies, which are limited to 2D stress states. Secondly, intraply and interply damage can be introduced separately together with phenomenological models characterising the complex interaction between them. To model damage initiation and propagation in the composite laminate we employ the element removal scheme in Abaqus/explicit. i.e. a finite element was removed from the mesh as the threshold level of stresses, primarily in fibre direction, was achieved by the instantaneous stress at all the nodes of this element. A combined approach employing advantages of both linear-elastic fracture mechanics (LEFM) and damage mechanics used for delamination modelling is also discussed in this section

Hashin proposed a failure criterion for a unidirectional (UD) composite to model four distinct failure modes independently: fibre damage in tension and compression as well as matrix tensile and compressive failure [31]. Hashin's failure criterion has been used extensively in industry, although several studied have demonstrated that it cannot accurately predict initiation of matrix compressive failure $[13,38]$. Alternatively, the damage model based on the theory proposed by Puck and Schurmann [32] has shown promise in predictive capabilities of a number of failure criteria in UD laminates $[13,38]$. In the present study, the Hashin criterion was used to estimate fibre damage, while the Puck's failure criterion is used to model matrix failure. These two criteria were implemented in a user-defined material model (VUMAT) in the general purpose finite element software Abaqus/explicit. A block diagram detailing the flow of logic in the implementation of VUMAT is shown in Figure 4.

\section{Hashin criteria for failure in elastic fibers:}

Fiber tensile failure $\left(\sigma_{11} \geq 0\right)$ 


$$
\left(\frac{\sigma_{11}}{S_{11}}\right)^{2}+\left(\frac{\sigma_{11}}{S_{12}}\right)^{2}+\left(\frac{\sigma_{11}}{S_{13}}\right)^{2}=1, d_{f t}=1 .
$$

Fiber compressive failure $\left(\sigma_{11}<0\right)$

$$
\left(\frac{\sigma_{11}}{X_{1 c}}\right)^{2}=1, d_{f c}=1 .
$$

\section{Puck criteria for failure in brittle epoxy matrix:}

Matrix failure

$$
\begin{gathered}
{\left[\left(\frac{\sigma_{11}}{2 X_{1 t}}\right)^{2}+\frac{\sigma_{22}^{2}}{\left|X_{2 t} \cdot X_{2 c}\right|}+\left(\frac{\sigma_{12}}{S_{12}}\right)^{2}\right]+\sigma_{22}\left(\frac{1}{X_{2 t}}+\frac{1}{X_{2 c}}\right)=1} \\
\sigma_{22}+\sigma_{33}>0, d_{m t}=1 \\
\sigma_{22}+\sigma_{33}<0, d_{m c}=1
\end{gathered}
$$

Here $\sigma_{11}, \sigma_{22}, \sigma_{33}, \sigma_{12}$ are components of the stress tensors at an integration point of an element; $d_{f t}, d_{f c}, d_{m t}, d_{m c}$ are the damage variables associated with failure modes in fibre tension, fibre compression, matrix tension and matrix compression, respectively; $X_{1 t}, X_{2 t}$ and $X_{2 c}$ are tensile failure stress in fibre direction, tensile failure stress in direction 2 (transverse to the fibre direction) and compressive failure stress in direction 2, respectively, while $S_{11}, S_{12}$ and $S_{13}$ are shear failure stresses in 1-2, 2-3 and 1-3 planes, respectively.

The values for the strength of a CFRP laminate used in this FE analysis are listed in Table 5. In drilling simulations, the element deletion approach used to remove the elements from the mesh was based on the value of damage variables as calculated from (2)-(4), applied to discrete damage modes in the modelled CFRP composite material. The element was removed when the maximum damage condition was satisfied at all of the section points at any integration point location of an element. The damage parameter, $d$ 
$\left(d \in \max \left\{d_{f t}, d_{f c}, d_{m t}, d_{m c}\right\}\right)$ based on above formulations was calculated such that when $d=1$, the element was removed from the mesh and offering no subsequent resistance to deformation.

\subsection{Delamination modelling}

Inter-ply delamination was modelled using cohesive-zone elements available in Abaqus/explicit. A pre-damage response of cohesive elements was characterised using elastic stiffness, calculated with an empirical formula suggested by Turon et al. [33-34]:

$$
K=\alpha \frac{E_{33}}{t}
$$

Here, $K$ is interface stiffness, $E_{33}$ is the Young's modulus of CFRP laminate in thickness direction, $t$ is the thickness of the individual ply and $\alpha$ is the adjusting parameter such that for its values greater than 50 , the loss of stiffness due to the presence of interface is less than $2 \%$. In our numerical experiments we assume, $\alpha=55$. The mixed-mode damage of cohesive elements was modelled with a typical bilinear traction-separation response (refer Figure 5) using the quadratic nominal-stress criterion.

The damage initiation condition has the following form:

$$
\left[\frac{t_{n}}{t_{n}^{0}}\right]^{2}+\left[\frac{t_{s}}{t_{s}^{0}}\right]^{2}+\left[\frac{t_{t}}{t_{t}^{0}}\right]^{2}=1 .
$$

Here $t_{n}, t_{s}$ and $t_{t}$ are the instantaneous components of normal and shear tractions at the interface, while $t_{n}^{0}, t_{s}^{0}$ and $t_{t}^{0}$ represent the peak values of nominal stress when the deformation is either purely normal to interface or purely in first or the second shear direction, respectively. Once the damage initiation condition is fulfilled, delamination starts and stiffness begins to degrade linearly linked to damage variable $D$ given by equation,

$$
D=\frac{\delta_{m}^{f}\left(\delta_{m}^{\max }-\delta_{m}^{0}\right)}{\delta_{m}^{\max }\left(\delta_{m}^{f}-\delta_{m}^{0}\right)} .
$$


Here $\delta_{m}^{f}$ is the mixed-mode displacement at complete failure, $\delta_{m}^{\max }$ refers to the maximum value of the mixed-mode displacement and $\delta_{m}^{0}$ is the effective displacement at the damage initiation. The dependence of fracture energy on mode-mixity was defined using a power-law fracture criterion,

$$
\left[\frac{G_{n}}{G_{n}^{c}}\right]^{\beta}+\left[\frac{G_{s}}{G_{s}^{c}}\right]^{\beta}+\left[\frac{G_{t}}{G_{t}^{c}}\right]^{\beta}=1 .
$$

Here, $G_{n}, G_{s}$ and $G_{t}$ are the instantaneous fracture energies in normal, and shear directions, whereas, $G_{n}^{c}, G_{s}^{c}$ and $G_{t}^{c}$ refer to the critical fracture energies required to cause failure in the normal, the first, and the second shear direction respectively. The elastic and strength properties of cohesive elements used in the simulation are listed in Table 6. The elastic traction values were estimated from (5), while maximum stress and fracture energy values were taken from [35] owing to similarity of composite laminate.

\subsection{FE model setup}

\subsubsection{Geometrical modelling and boundary conditions}

A 3D FE model of drilling was developed which consists of a TiN coated Jobber carbide twist drill bit, the cross-ply composite laminate and the backing plate with appropriate boundary conditions as shown in Figure 6.

A $2 \mathrm{~mm}$ thick laminate in the model consisted of 16 plies with an individual ply thickness of $0.125 \mathrm{~mm}$ in the stacking sequence $\left[0_{4} / 90_{8} / \mathrm{O}_{4}\right]$. The local co-ordinate systems were defied to account for orientations of individual plies and to model the laminate and material behaviour precisely. All the nodes of bottom surface of the CFRP laminate were tied to the upper surface of the backing plate using a tie constraint to represent the experimental boundary condition. 
In the FE analysis, the twist drill and the backing plate were modelled as discrete rigid bodies for following reasons:

1) Elastic stiffness of the TiN coated Jobber carbide twist drill is in the range of 500 - $700 \mathrm{GPa}$ as compared to $127 \mathrm{GPa}$ for the composite laminate in the principal fibre direction and can be safely regarded as a rigid body, reducing the computational cost involved in the highly resource-consuming drilling simulations.

2) The backing plate, tied with the CFRP laminate (refer Figure 1) was used to support the laminate during drilling in order to mitigate exit delamination. There is no specific interest to examine its effect on drilling. Thus it was considered to be appropriate to model the backing plate as a rigid body, in order to reduce the overall computational cost.

The twist drill was fed into the workpiece in the axial direction using a velocity boundary condition, which represents the feed rate during experiments. An angular velocity about the drill axis equivalent to the spindle speed of $2500 \mathrm{rpm}$ was superimposed on the drill geometry. Three sets of simulations were carried out with three different feed rates (250 $\mathrm{mm} / \mathrm{min}, 300 \mathrm{~mm} / \mathrm{min}, 500 \mathrm{~mm} / \mathrm{min}$ ) a constant spindle speed (2500 rpm).

\subsubsection{Finite elements and mesh sensitivity}

In the rectangular composite plate modelled, each ply was represented by two eight-node linear brick elements with reduced integration, C3D8R through its thickness in the vicinity of the drilling zone, and two six node triangular wedge elements away from it. The mesh sensitivity study is very important in simulations involving high deformations and non-linear material behaviour. Thus a vigorous mesh-sensitivity study was carried out to obtain a computationally accurate finite element mesh. In the current study all results are presented based on studies carried out on an optimised mesh. Computing clock time was reduced by introducing different mesh sizes in distinct regions of the FE model. A planar mesh size of $0.25 \mathrm{~mm} \times 0.25 \mathrm{~mm}$ (in 1-2 plane) in the vicinity of the drilling area was used while a coarser 
mesh of $1.25 \mathrm{~mm} \times 1.25 \mathrm{~mm}$ was used in area away from the zone of interest. Localised stiffness reduction due to internal damage can cause excessive element distortion that could lead to difficulties in numerical convergence. To resolve this numerical issue, 'distortion control' was used in Abaqus, and damage variables were limited to a maximum value of 0.999. At each ply interface, cohesive elements of type COH3D8 with a thickness of $10 \mu \mathrm{m}$, were embedded and used to model delamination initiation and growth with the failure criterion discussed in section 3.3. The degradation parameters were set to 0.99 and the failed cohesive elements were removed from the FE model, once the failure criteria were satisfied. It was observed in the wave stability study that cohesive zone elements govern stability of the solution (due to near-zero element size) with a very low stable time increment of the order of $10^{-9} \mathrm{~s}$ which affected the overall solution run time and, hence, a selective mass-scaling technique was used. The density of cohesive zone elements was artificially increased by a factor of 25 so that the total mass of the laminate remained practically unaffected.

\subsubsection{Material properties}

The material properties of CFRP laminate used in FE analysis are listed in Tables 1 and 5. The values of fracture toughness for intra and inter laminar damage were taken from literature [29] as listed in Table 6, which include elastic stiffness, strength and fracture energy. Damage evolution under mixed-mode loading was based on the BenzeggaghKenane fracture-energy law [36].

\subsubsection{Drill-work piece contact}

The contact and friction parameters used in the simulations were based on a number of experimental factors such as cutting speed, feed rate, drill geometry and surface properties. Contacts between the twist drill and the CFRP laminate and all contacted plies of the laminate were defined by the general contact algorithm available in Abaqus/explicit. This algorithm generated the contact forces based on the penalty-enforced contact method. The 
friction coefficient $\mu$ is used to account for the shear stress of the surface traction $\tau$ with the contact pressure $p$ and can be represented as $\tau=\mu p$. In this case, the frictional contact between a drill and composite laminate was modelled with a constant coefficient of friction of 0.3 [37]. The models require on average 62 hours on 24 Intel quad-core processors with 48 GB RAM each to finish the analysis using High Performance Computing (HPC) facility available at Loughborough University.

\subsection{Results and discussion}

\subsubsection{FE model validation}

In order to allow a better comparison of the experimental and simulated thrust force and torque in drilling CFRP, a mid-range feed of $300 \mathrm{~mm} / \mathrm{min}$ was chosen from the experimental feed data with a spindle speed $2500 \mathrm{rpm}(23.6 \mathrm{~m} / \mathrm{min}$ cutting speed at the drill edge). The FE simulations were carried out using these process parameters and later used to predict the thrust force and torque for other feed rates. Figure 7 (a) and (b) shows the experimental and simulated data for the thrust force and torque in drilling of UD-CFRP T300/LTM45-EL laminate.

Apparently, the average maximum thrust force (obtained for the period of complete drill engagement) in the experimental trial was $172.5 \mathrm{~N}$ whereas FE model estimated $180.6 \mathrm{~N}$. The experimentally measured torque was $103.1 \mathrm{~N}-\mathrm{cm}$ compared to the torque value predicted as $112.2 \mathrm{~N}-\mathrm{cm}$ by FE simulation. This shows that the FE model estimated the thrust force and torque accurately, with $4.69 \%$ and $8.82 \%$ deviation from the respective test results. It should be noted that several factors could improve the accuracy of the simulation results. Amongst these is the use of a more realistic friction model, improved damage model, inclusion of thermal effect and accounting of drill wear effects. The type of element used to discretize the composite component may also affect results. Discrepancy in torque predictions may be due to overly stiff $3 \mathrm{D}$ solid elements used with the default reducedintegration scheme available in Abaqus/explicit. Artificially relaxing the stiffness of the solid 
elements may address this issue, this will be a topic of future research and is not addressed in the current study.

\subsubsection{Prediction of thrust force and torque}

Figure 8 (a) shows the effect of cutting parameters on the average maximum thrust force. The FE model estimated the thrust force between $120.9 \mathrm{~N}$ and $212.5 \mathrm{~N}$ for the range of feed rates modelled. The obtained results indicate that thrust force in drilling increases with the increasing feed rate. It can be observed from Figure 8 (a) that the average maximum thrust force was the highest at the feed rate of $500 \mathrm{~mm} / \mathrm{min}$ and lowest at the feed rate of 150 $\mathrm{mm} / \mathrm{min}$ for the constant spindle speed of $2500 \mathrm{rpm}$. Comparing the levels of thrust force for different feed rates, it was observed that when feed rate was increased from $150 \mathrm{~mm} / \mathrm{min}$ to $300 \mathrm{~mm} / \mathrm{min}$ and $500 \mathrm{~mm} / \mathrm{min}$ the thrust force increased by $50 \%$ and $76 \%$ respectively. Figure 8 (b) shows the drilling torque corresponding to different feed rates. In contrast to the thrust force, the increase of feed rate to the maximum showed level resulted in a significantly higher increase in the magnitude of the torque by $136 \%$.

\subsubsection{Delamination}

The delamination profiles obtained with $\mathrm{X} \mu \mathrm{CT}$ for drill entry and exit were processed using an image processing code developed in Matlab, and the corresponding delamination factor was calculated using the pixel-based technique as discussed in Section 2.6. The results of FE simulations of delamination are compared qualitatively (refer Figure 9 - row 2 and 4).

The delamination factors in FE analysis were calculated using a simple methodology, where the ratio of total number of cohesive elements before and after the drilling simulation was calculated using a python script. The corresponding delamination factors for drill entry and drill exit are listed in Table 7.

It can be seen that the FE model over-predicted the magnitude of delamination factor for each set of machining parameter for the drill exit case though the overall shape was rather well estimated in this analysis. This difference is most likely due to inaccuracy in the 
estimated value of the elastic stiffness and tractions of cohesive elements obtained with the standard approach as discussed in section 3.3. To obtain an accurate estimate, the value of the adjusting factor $\alpha$ in (5) should be increased.

For a spindle speed of $2500 \mathrm{rpm}$, with increasing level of feed rates from $150 \mathrm{~mm} / \mathrm{min}$ to $300 \mathrm{~mm} / \mathrm{min}$ and $500 \mathrm{~mm} / \mathrm{min}$ resulted in the delamination factor at entry increasing by $28 \%$ and $29 \%$, and delamination factor at drill exit increasing by $65 \%$ and $153 \%$ respectively. The FE simulation predicts the rise of delamination factor at drill entry between $26 \%-29 \%$ while at drill exit between $70 \%-170 \%$. Thus, as a general guideline, where possible, low feeds should be used while drilling CFRP composites in order to mitigate delamination at drill exit.

\subsubsection{Drilling-parameter optimisation study}

The validated FE model of drilling was utilised to select optimal machining parameters in order to alleviate damage in CFRP composites. The FE model setup including back-up plate, as used in the previous studies, was also retained for these situations. A combination of range of drill feed rates and cutting speeds were chosen as shown below in Table 8.

The effects of different combinations of machining parameters listed in the table on the drilling thrust force, torque and exit delamination were studied using the validated FE model. The results of these studies are shown in Figure 9. The drill exit delamination was only considered due to significantly lower extent of drill entry delamination as discussed in

\section{Section 3.5.3.}

It can be observed from Figure 10, that the thrust force, torque and delamination factor increased with increase in the drill feed, while decreasing with increase in the cutting speed. For instance, when drill feed was increased $16 \mathrm{~mm} / \mathrm{min}$ to $500 \mathrm{~mm} / \mathrm{min}$ at cutting speed of $600 \mathrm{rpm}$, thrust force increased by $570 \%$, torque increased by $636 \%$ and damage increased by $410 \%$; the similar trend was observed for all combinations of drill feeds. When cutting speed was increased from $40 \mathrm{rpm}$ to $5000 \mathrm{rpm}$ for drill feed of $150 \mathrm{~mm} / \mathrm{min}$, the thrust force 
decreased by $9.24 \%$ while torque reduced by $43 \%$ and damage reduced by $46 \%$; similar qualitative observations can be made for all combinations of cutting speeds. Moreover, an increase in the thrust force was more precipitous compared to that of the torque for all combinations of machining parameters. Hence the use of low feed and high speed is recommended for mitigation of drilling-induced damage in CFRP composites.

There were very few attempts $[13,17,21,23,26-28]$ prior to this study, to model drilling in composites and were predominantly based on a plethora of assumptions and simplifications, hence direct comparison of our FE results with these were not deemed practical. For example, Singh et al. [26] developed FE model of drilling in glass-fibre/epoxy composites that considered drill topology and drill-workpiece reasonably, though it failed to account for interply delamination and though-thickness behaviour of laminate owing to use of twodimensional shell elements. Durão et al. [27] assumed that axial force exerted by drill tip was responsible for delamination initiation and hence drill was modelled in the form of sharp conical nose indenter, which failed to account for accurate interaction with the workpiece. Strenkowski et al. [28] developed an analytical model to account for drilling induced thrust force and torque however underlying delamination was not addressed. The model proposed in this study has none of the drawbacks observed in the above mentioned studies [26-28] and is a physically representative model of composite deformation and damage when subjected to invasive machining processes.

\section{Conclusions}

In this paper the effect of discrete machining parameters on thrust force and torque in drilling of a cross-ply T300/LTM45-EL composite laminate was investigated both experimentally and numerically. Drilling-induced delamination, being one of the critical modes of damage in CFRP, was quantified experimentally from microtomography images after appropriate image processing. A 3D FE model of drilling in CFRP was developed. The underlying user-defined material model accounts for an orthotropic material response along with a stress-based 
damage criterion at the ply-level. Element deletion approach based on the threshold stress levels in carbon fiber and epoxy matrix materials was implemented in the material model to allow for the hole-making process in drilling. The following observations were made in this study

- $\quad$ FE model predicted drilling thrust force and torque with reasonable accuracy when compared to experimental results.

- Interply delamination modelled by embedding cohesive zone elements between the adjacent plies in the composite laminate predicts the delamination shape and size at drill entry with reasonable accuracy, while at drill exit both delamination shape and size were slightly over-estimated.

- The validated drilling model was used to determine optimal drilling parameters. It was observed that the thrust force, torque and delamination damage increased abruptly with an increase in the feed rate, but reduced gradually with increasing cutting speeds. Our numerical studies indicate that low feed rates $(<150 \mathrm{~mm} / \mathrm{min})$ and high cutting speeds (> $600 \mathrm{rpm}$ ) are ideal for drilling carbon/epoxy laminates within a range of drill parameters used in this study.

Next, a promising non-traditional drilling technique, called ultrasonically assisted drilling will be critically assessed for its advantages over conventional drilling techniques to reduce machining-induced damage in CFRP composites. We mention here that we have had success with a unique finite element modelling approach, to be reported in the near future.

\section{References}

[1] Hinchcliffe M. Characterisation of Bond Line Porosity.

http://seit.unsw.adfa.edu.au/ojs/index.php/juer/article/viewFile/139/95, 2012-04-03.

[2] König W, Wulf C, Graß P, Willerscheid H. Machining of fibre reinforced plastics. CIRP Annals - Manufacturing Technology. 1985;34(2):537-48. 
[3] Davim JP, Reis P. Drilling carbon fibre reinforced plastics manufactured by autoclaveexperimental and statistical study. Materials and Design. 2003;24(5):315-24.

[4] Zitoune R, Collombet F, Lachaud F, Piquet R, Pasquet P. Experiment-calculation comparison of the cutting conditions representative of the long fiber composite drilling phase. Composites Science and Technology. 2005;65(3-4):455-66.

[5] Davim, J.P (Ed.), Drilling of Composite Materials, NOVA Publishers, New York, 2009 ISBN: 978-1-60741-170-5

[6] Davim, J.P. (Ed.), Machining Composite Materials, ISTE-Wiley, London, 2009 ISBN: 9781-84821-103-4.

[7] Davim JP, Reis P, António CC. Experimental study of drilling glass fiber reinforced plastics (GFRP) manufactured by hand lay-up. Composites Science and Technology. $2004 ; 64(2): 289-97$

[8]Torres M, Gonzalez JL, Hernandez H. Residual strength and fracture path for drilled epoxy-glass composites. Advanced Material Research. 2009;65:89-96.

[9] Persson E, Eriksson I, Zackrisson L. Effects of hole machining defects on strength and fatigue life of composite laminates. Composites Part A: Applied Science and Manufacturing. $1997 ; 28(2): 141-51$.

[10] Astrom B. Manufacturing of Polymer Composites: Chapman-Hill; 1997.

[11] Abrate S, Walton DA. Machining of composite materials. Part I: Traditional methods. Composites Manufacturing. 1992;3(2):75-83.

[12] Teti R. Machining of composite materials. CIRP Annals - Manufacturing Technology. 2002;51(2):611-34.

[13] Dandekar CR, Shin YC. Modeling of machining of composite materials: A review. International Journal of Machine Tools and Manufacture. 2012;57:102-21.

[14] Hocheng $\mathrm{H}$, Tsao CC. The path towards delamination-free drilling of composite materials. Journal of Materials Processing Technology. 2005;167(2-3):251-64. 
[15] Santiuste C, Miguélez H, Soldani X. Out-of-plane failure mechanisms in LFRP composite cutting. Composite Structures. 2011;93(11):2706-13.

[16] Soldani X, Santiuste C, Muñoz-Sánchez A, Miguélez MH. Influence of tool geometry and numerical parameters when modelling orthogonal cutting of LFRP composites. Composites Part A: Applied Science and Manufacturing. 2011; 42(9):1205-16.

[17] Mkaddem A, Demirci I, Mansori ME. A micro-macro combined approach using FEM for modelling of machining of FRP composites: Cutting forces analysis. Composites Science and Technology. 2008;68(15-16):3123-7.

[18] The Mathworks Inc. Matlab 10.1. Natick , MA2000.

[19] Zhou G, Lloyd P. Design, manufacture and evaluation of bending behaviour of composite beams embedded with SMA wires. Composites Science and Technology. 2009;69(13):2034-41.

[20] Campos Rubio J, Abrao AM, Faria PE, Correia AE, Davim JP. Effects of high speed in the drilling of glass fibre reinforced plastic: Evaluation of the delamination factor. International Journal of Machine Tools and Manufacture. 2008;48(6):715-20.

[21] Tsao CC, Hocheng $\mathrm{H}$. Evaluation of thrust force and surface roughness in drilling composite material using Taguchi analysis and neural network. Journal of Materials Processing Technology. 2008;203(1-3):342-8.

[22] Chen W-C. Some experimental investigations in the drilling of carbon fiber-reinforced plastic (CFRP) composite laminates. International Journal of Machine Tools and Manufacture. 1997;37(8):1097-1108.

[23] Davim JP, Rubio JC, Abrao AM. A novel approach based on digital image analysis to evaluate the delamination factor after drilling composite laminates. Composites Science and Technology. 2007;67(9):1939-1945

[24] Khashaba UA, El-Sonbaty IA, Selmy AI, Megahed AA. Machinability analysis in drilling woven GFR/epoxy composites: Part I - Effect of machining parameters. Composites Part A: Applied Science and Manufacturing. 2010;41(3):391-400. 
[25] Sardiñas RQ, Reis P, Davim JP. Multi-objective optimization of cutting parameters for drilling laminate composite materials by using genetic algorithms. Composites Science and Technology. 2006;66(15):3083-8.

[26] Singh I, Bhatnagar N, Viswanath P. Drilling of uni-directional glass fiber reinforced plastics: Experimental and finite element study. Materials \&amp; Design. 2008;29(2):546-53. [27] Durão LMP, de Moura MFSF, Marques AT. Numerical prediction of delamination onset in carbon/epoxy composites drilling. Engineering Fracture Mechanics. 2008;75(9):2767-78. [28] Strenkowski JS, Hsieh CC, Shih AJ. An analytical finite element technique for predicting thrust force and torque in drilling. International Journal of Machine Tools and Manufacture. $2004 ; 44(12-13): 1413-21$

[29] Hibbitt, Karlsson \& Sorensen Inc., ABAQUS version 6.11; 2011.

[30] Phadnis VA, Makhdum F, Roy A, Silberschmidt VV. Drilling induced damage in CFRP laminates :Experimental and numerical analysis. Solid State Phenomena. 2012;188:150-157. [31] Hashin Z. Analysis of stiffness reduction of cracked cross-ply laminates. Engineering Fracture Mechanics. 1986; 5: 771-778.

[32] Puck A, Schürmann $H$. Failure analysis of FRP laminates by means of physically based phenomenological models. Composites Science and Technology. 1998; 7: 1045-67. [33] Turon A, Camanho PP, Costa J, Renart J. Accurate simulation of delamination growth under mixed-mode loading using cohesive elements: Definition of interlaminar strengths and elastic stiffness. Composite Structures. 2010;92(8):1857-64.

[34] Turon A, Camanho PP, Costa J, Dávila CG. A damage model for the simulation of delamination in advanced composites under variable-mode loading. Mechanics of Materials. 2006; 38(11):1072-89.

[35] Hallett SR, Green BG, Jiang WG, Wisnom MR. An experimental and numerical investigation into the damage mechanisms in notched composites. Composites Part A: Applied Science and Manufacturing. 2009;40(5):613-24. 
[36] Benzeggagh M., Kenane M. Measurement of mixed-Mode delamination fracture toughness of unidirectional glass/epoxy Composites with mixed-mode bending apparatus. Composite Science and Technology. 1996; 56: 439-441

[37] Klinkova O, Rech J, Drapier S, Bergheau J-M. Characterization of friction properties at the workmaterial/cutting tool interface during the machining of randomly structured carbon fibers reinforced polymer with carbide tools under dry conditions. Tribology International. $2011 ; 44(12): 2050-8$.

[38] Hinton MJ, Kaddour AS, Soden PD. A comparison of the predictive capabilities of current failure theories for composite laminates, judged against experimental evidence. Composites Science and Technology. 2002; 62(12-13):1725-97.

\section{Figures and tables}

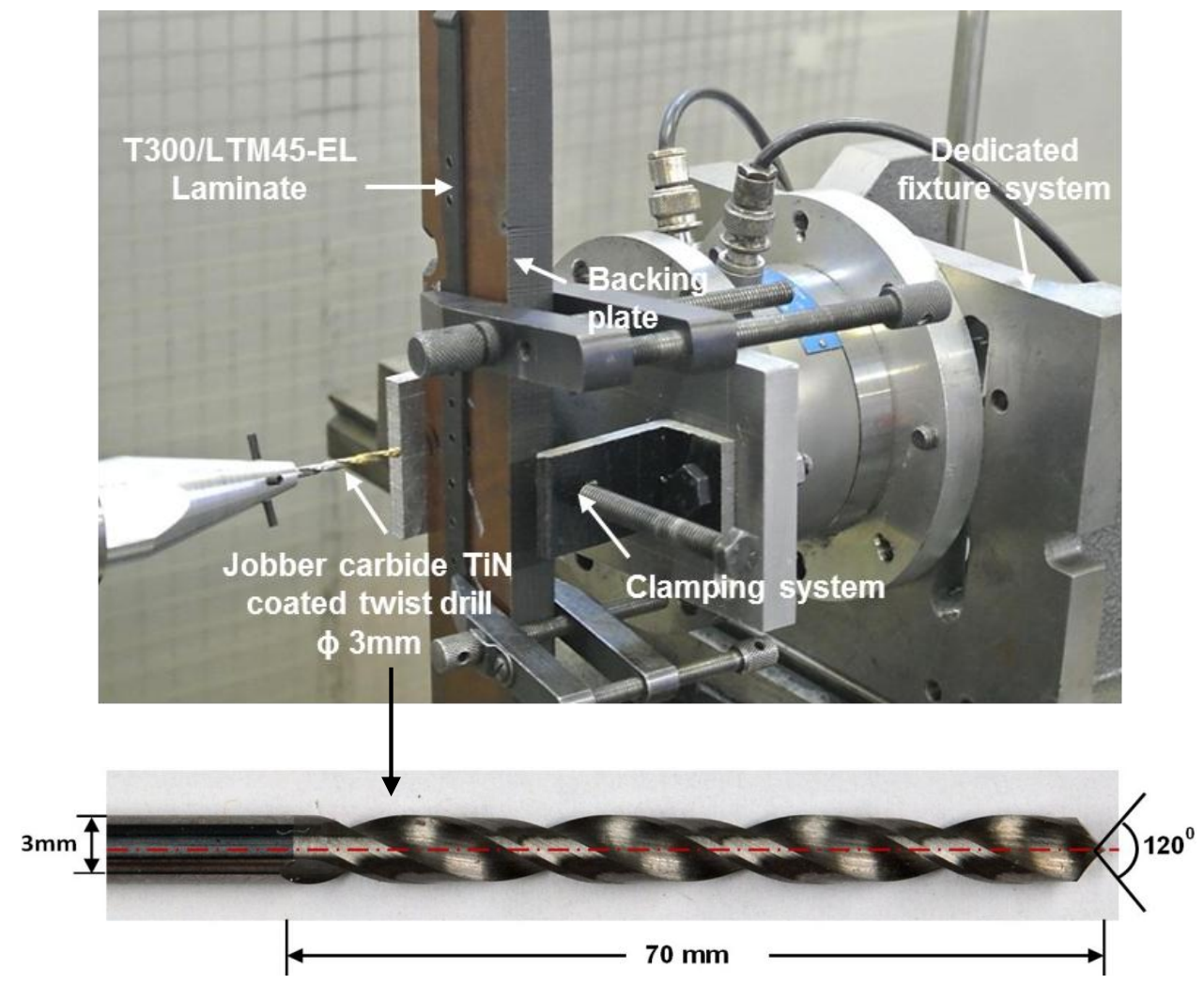

Figure 1. Experimental setup for drilling T300/ LTM45-EL laminate 


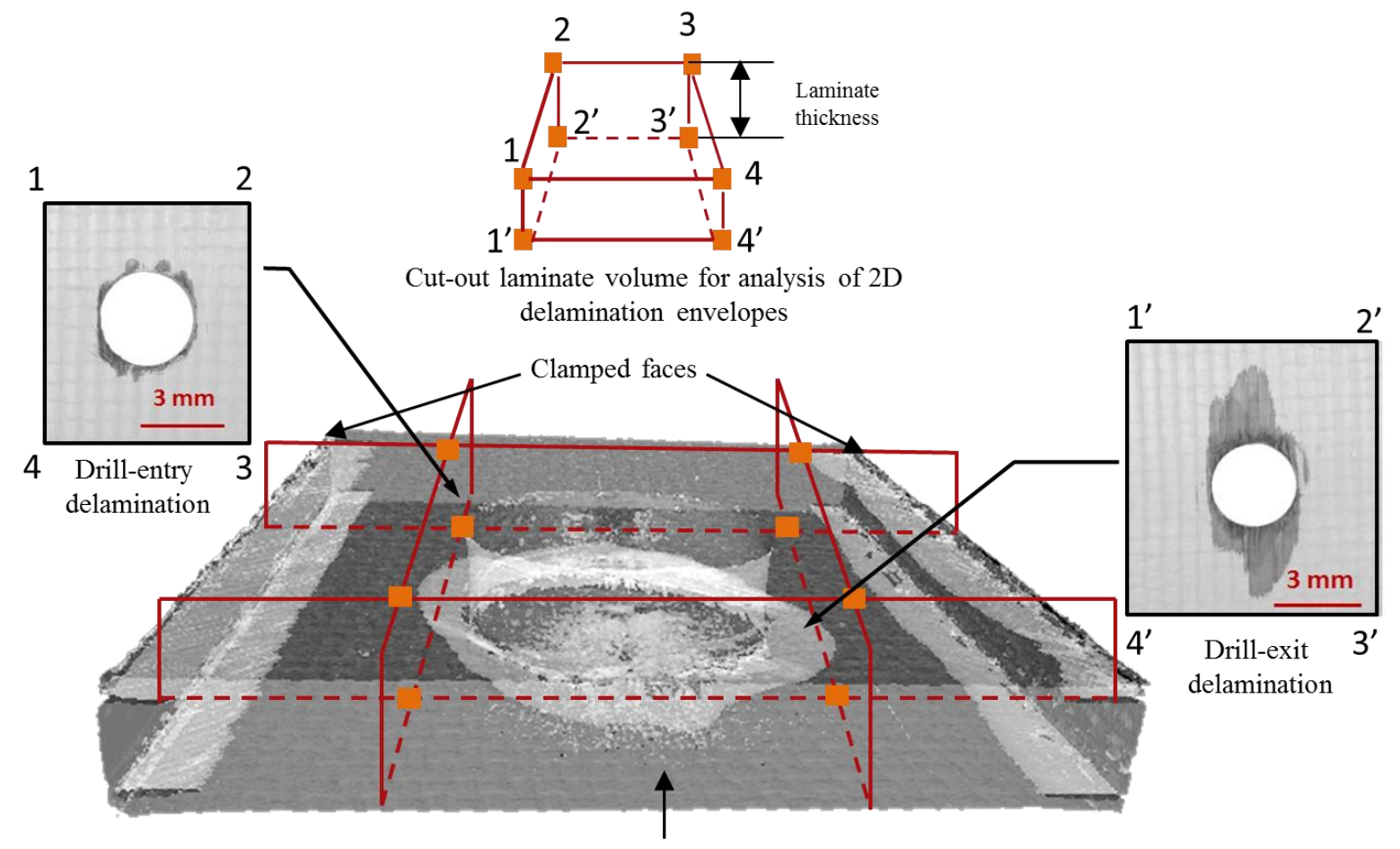

$\mathrm{X} \mu \mathrm{CT}$ image of drilled T300/LTM-45EL laminate

Figure 2. Methodology for selection of delamination contours at drill-entry and exit (example is shown for feed rate of $150 \mathrm{~mm} / \mathrm{min}$ )

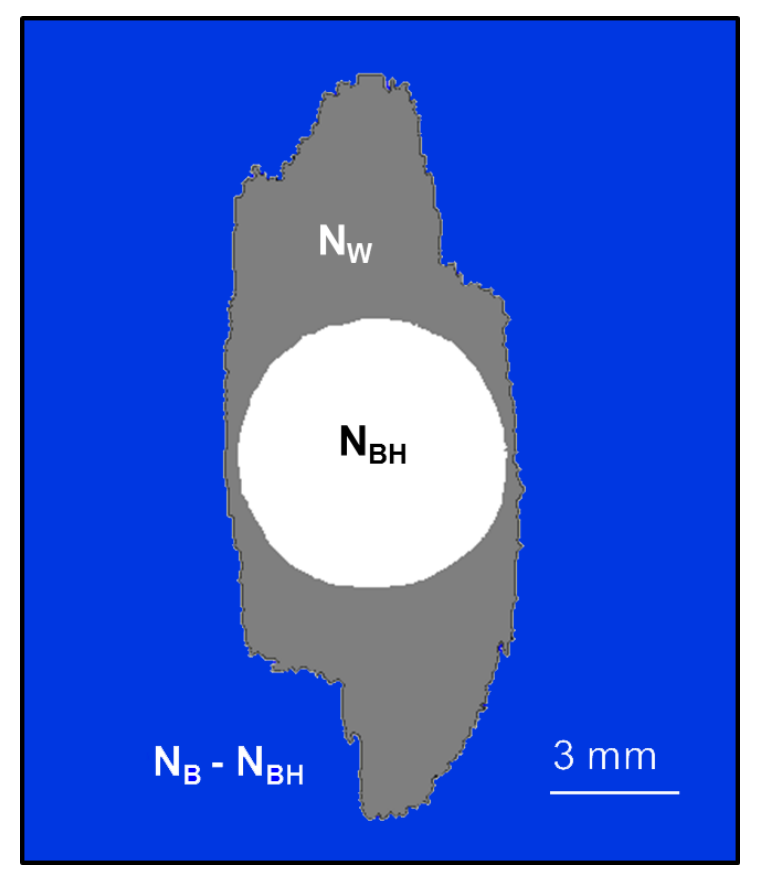

Figure 3. Scanned area at drill exit showing terminology for delamination quantification (Feed rate $=150 \mathrm{~mm} / \mathrm{min}$ ) 


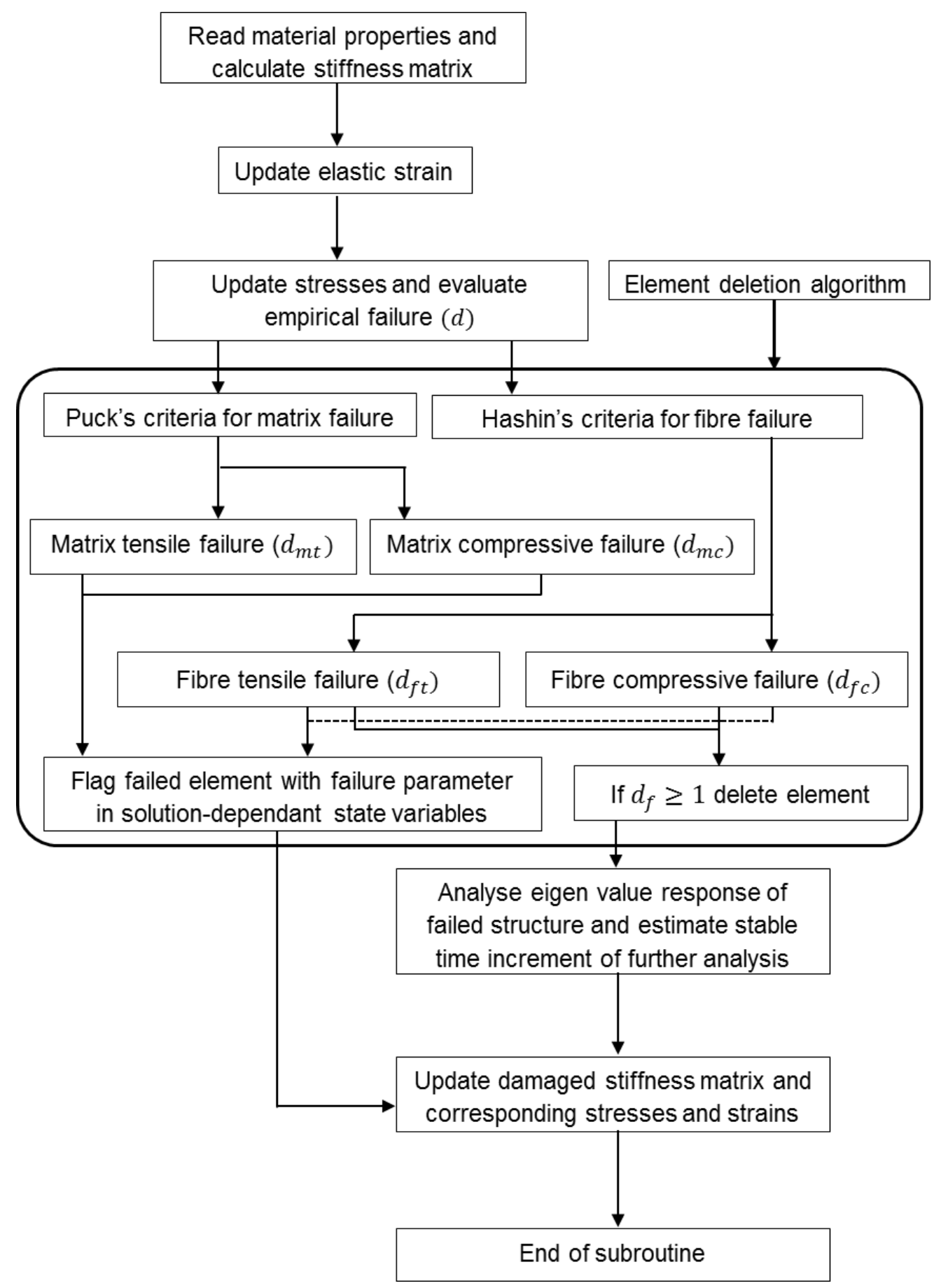

Figure 4. Algorithm showing implementation of VUMAT in Abaqus/explicit 


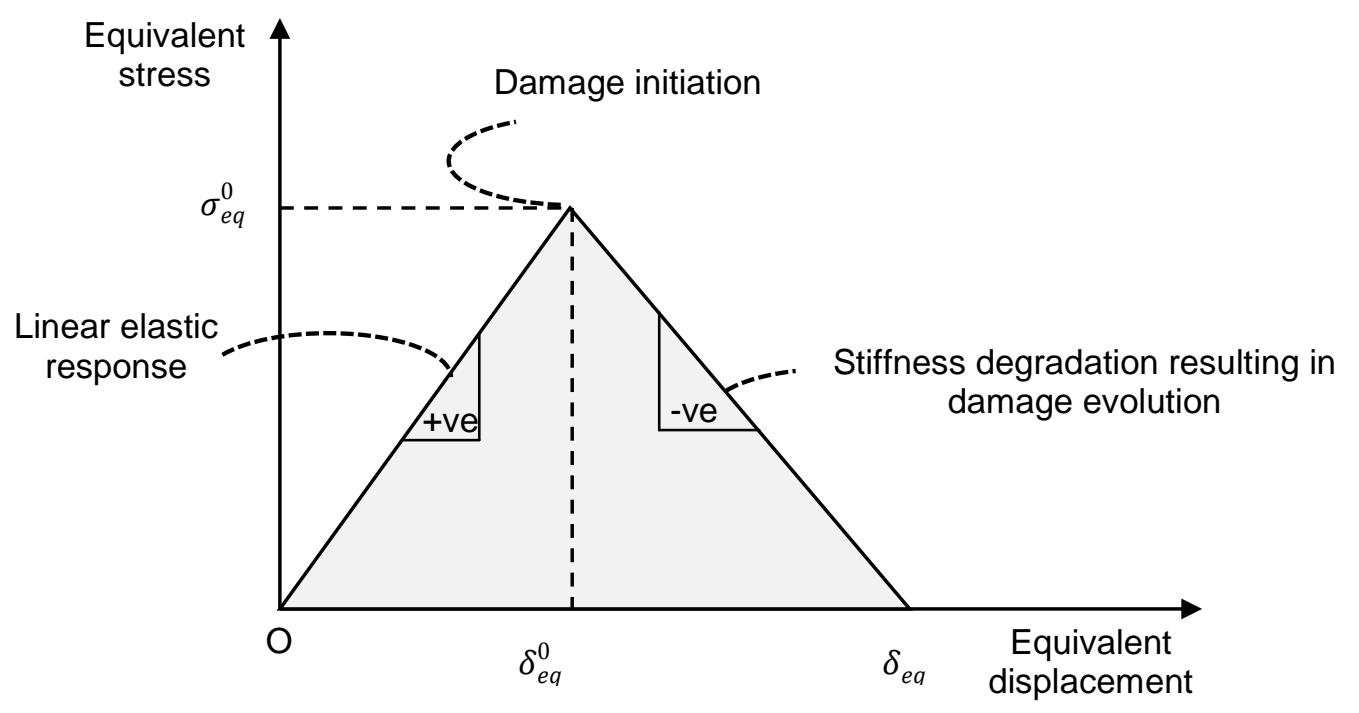

Figure 5. Damage initiation and evolution in cohesive elements for mode - I

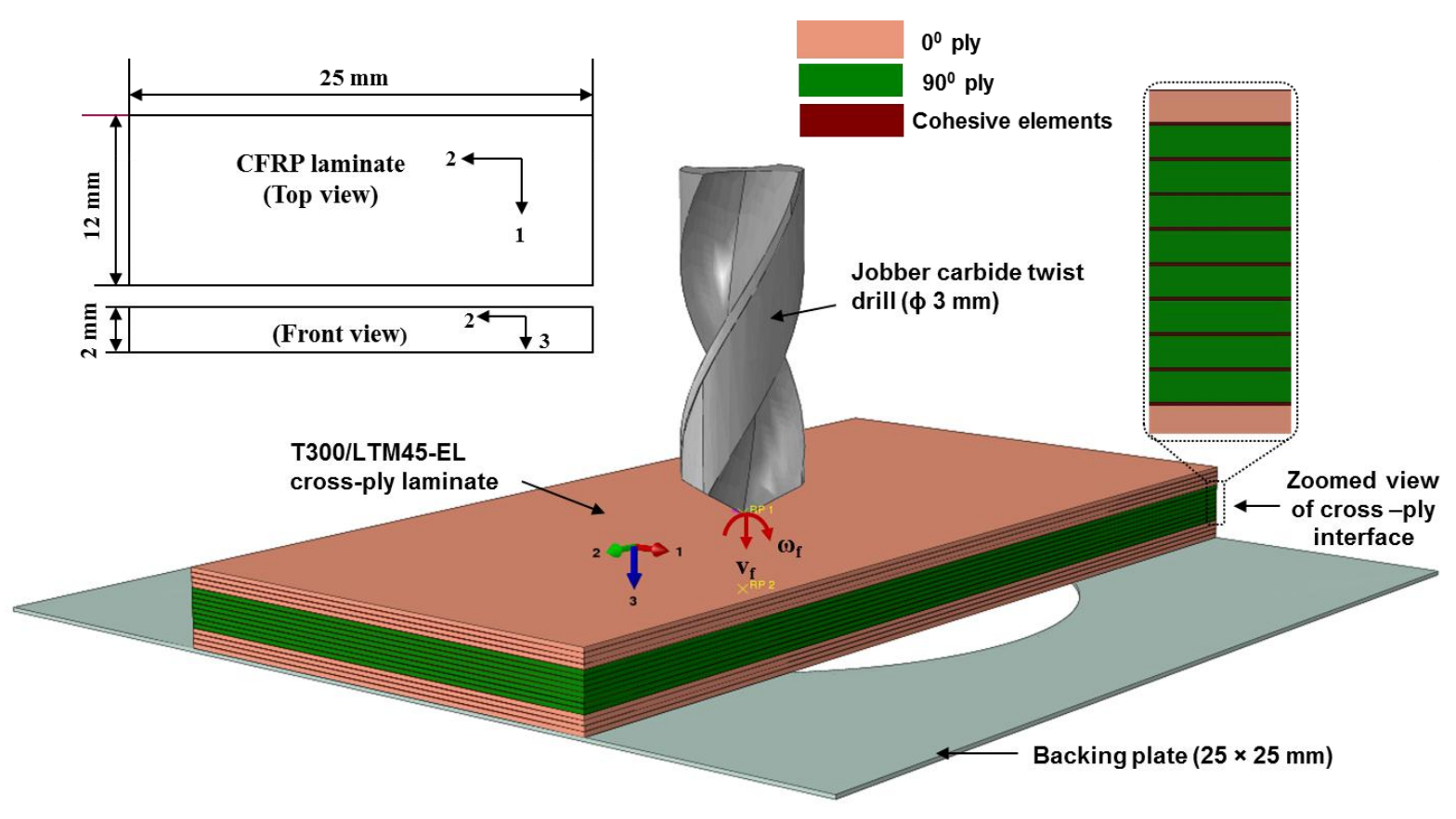

Figure 6. Finite-element model of drilling T300/LTM-45EL CFRP laminate 


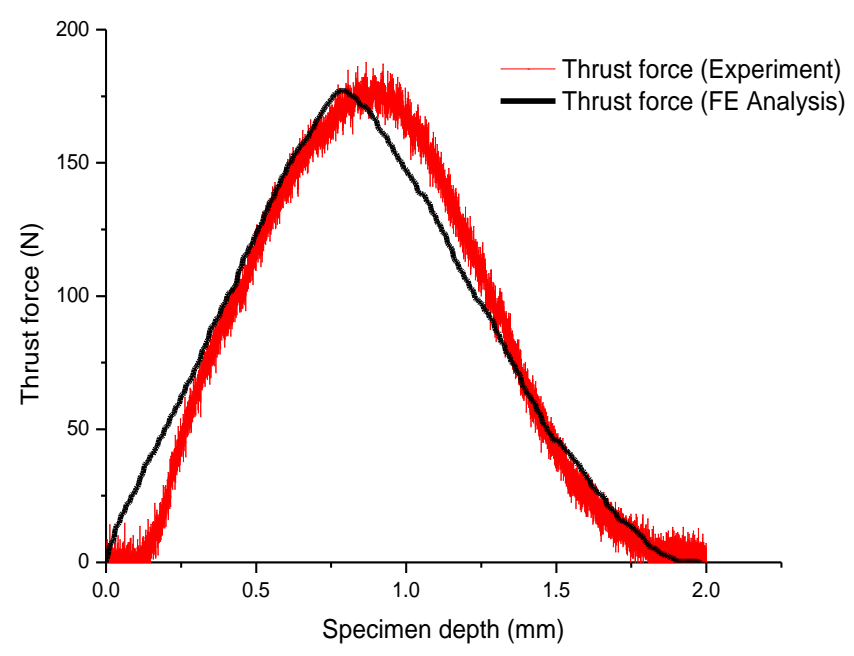

(a)

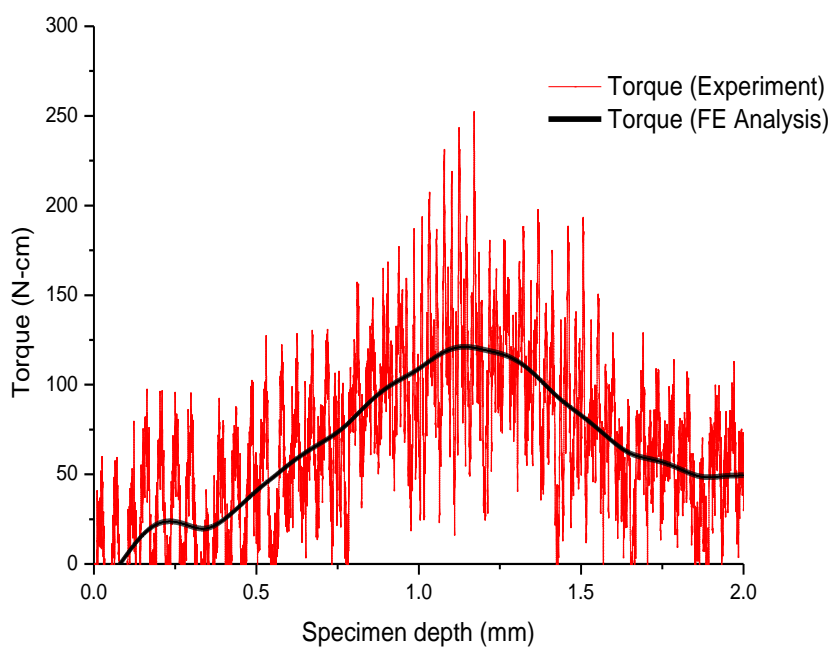

(b)

Figure 7. Comparison of simulated results: (a) thrust force, (b) torque
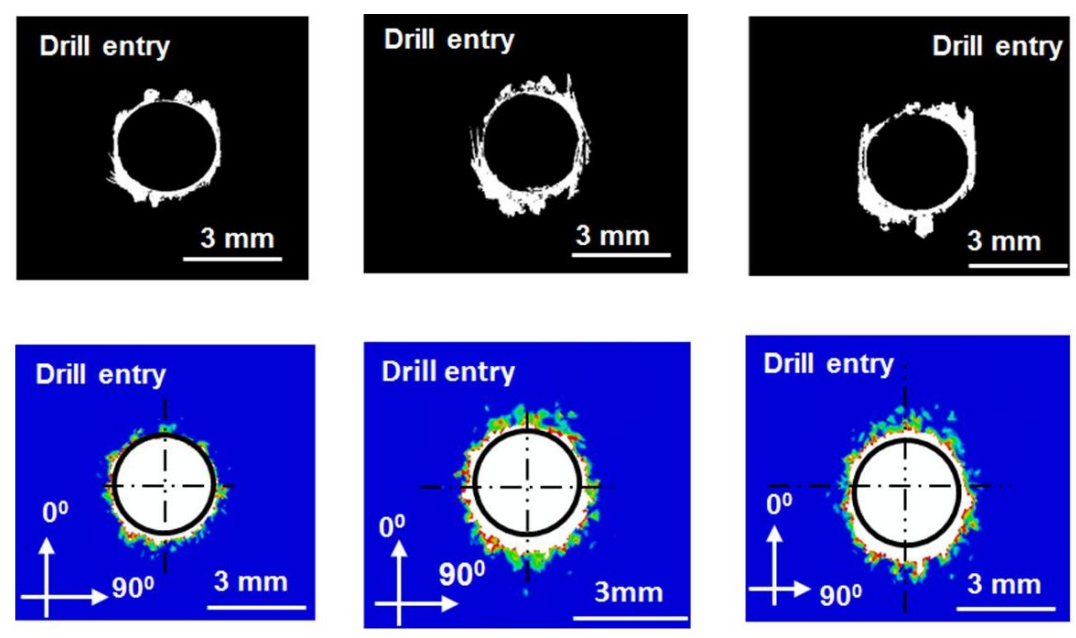

$f=150 \mathrm{~mm} / \mathrm{min}$

Damage variable, D

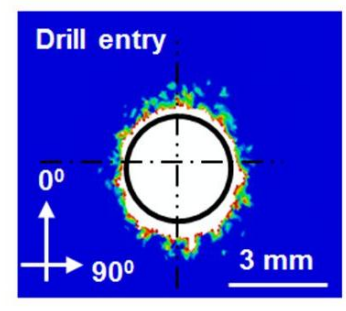

$f=500 \mathrm{~mm} / \mathrm{min}$

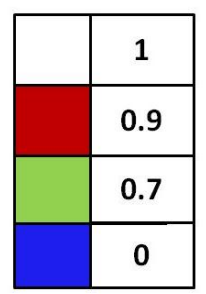

(a) 

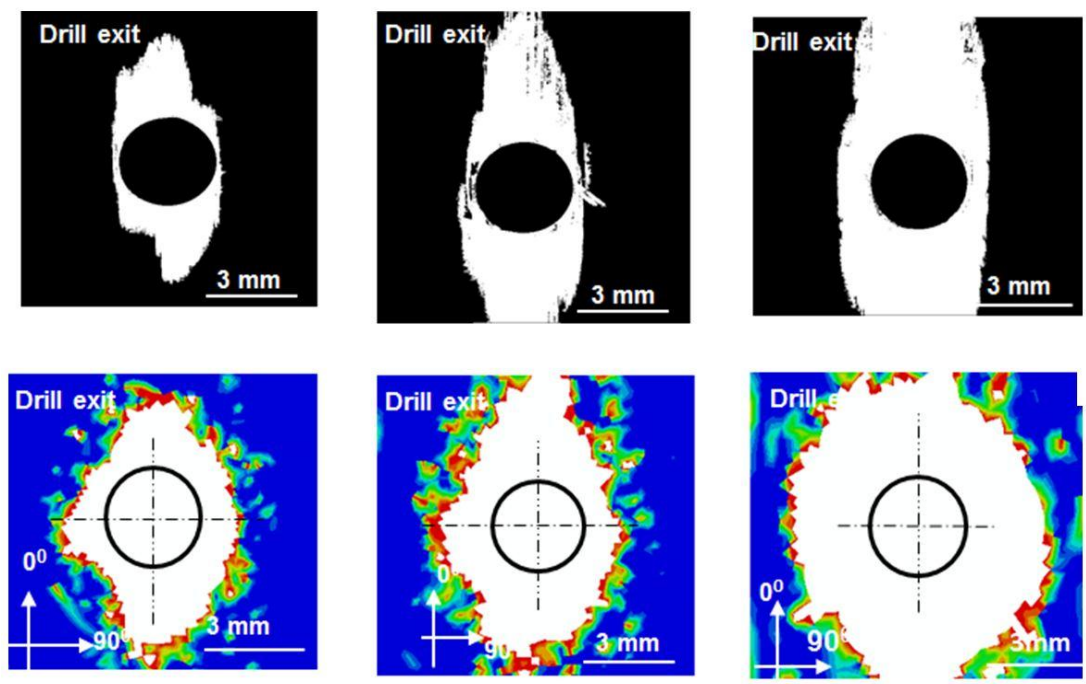

Damage variable, D

$f=150 \mathrm{~mm} / \mathrm{min}$

$f=300 \mathrm{~mm} / \mathrm{min}$

$f=500 \mathrm{~mm} / \mathrm{min}$

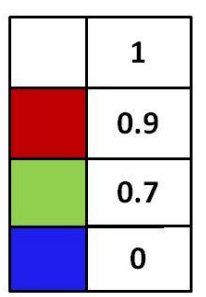

(b)

Figure 9. Delamination analyses for drill entry (a) and exit (b) using image processing (row 1 and 3), FE model (row 2 and 4)

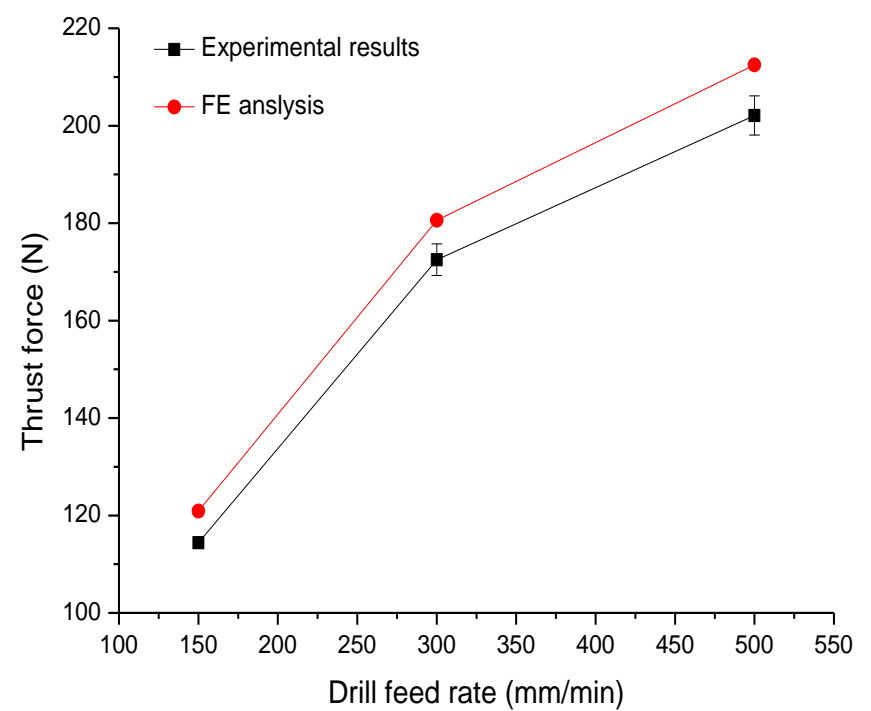

(a)

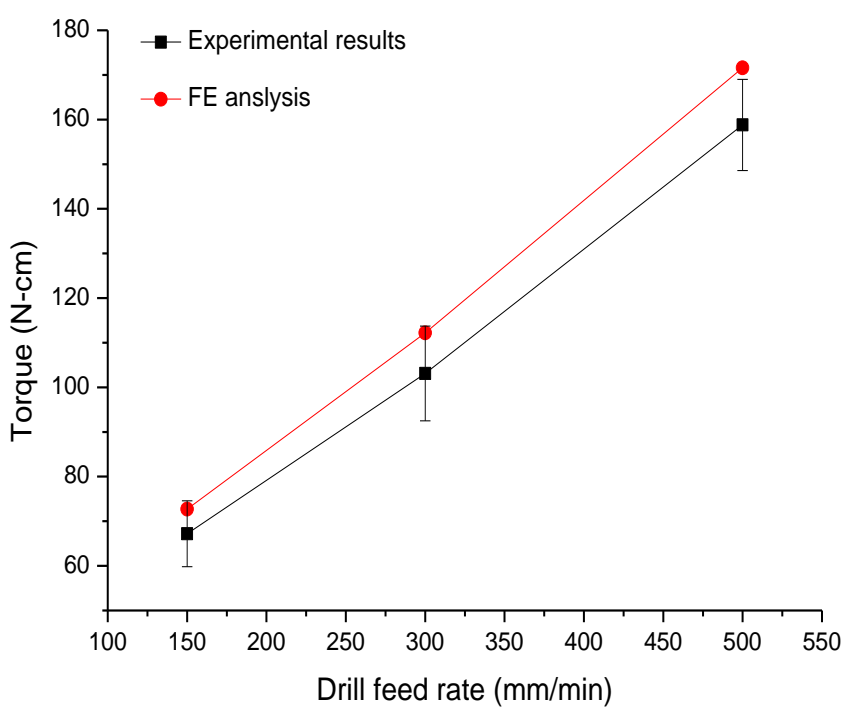

(b)

Figure 8. Comparison between experimental and FE results: (a) Thrust force (b) Torque 


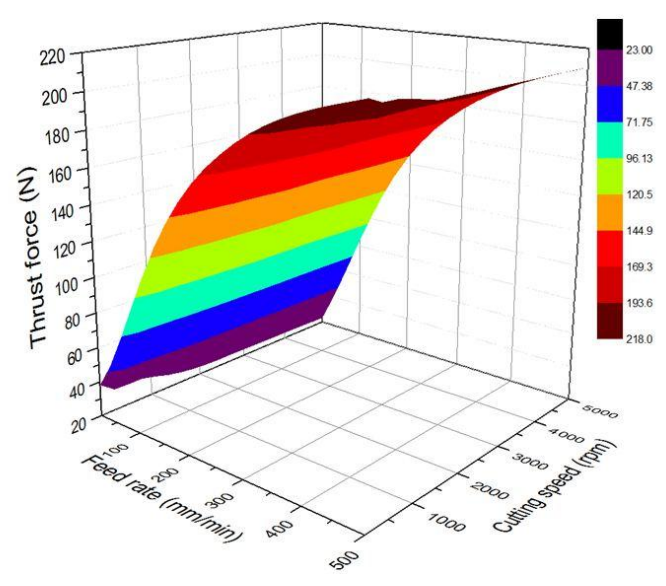

(a)

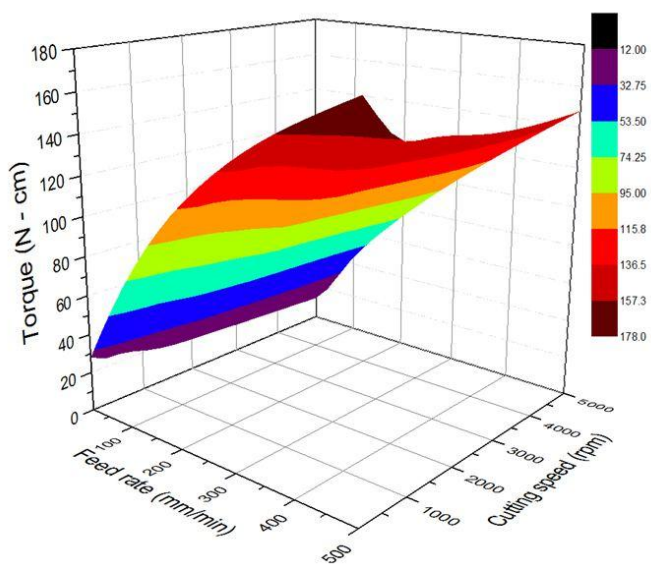

(b)

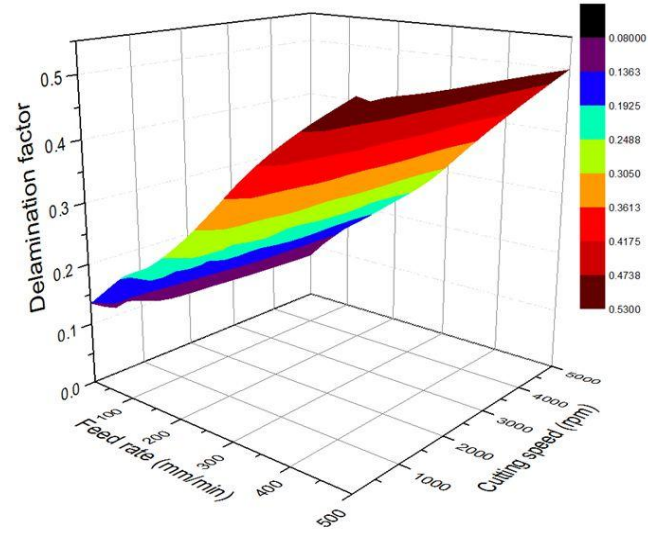

(c)

Figure 10. Effect of drill feed and cutting speed on thrust force (a), torque (b), and delamination factor(c)

Table 1. Mechanical properties of T300/LTM45-EL UD composite

\begin{tabular}{ccccccc}
\hline$E_{11}$ & $E_{22}=E_{33}$ & $v_{12}=v_{13}$ & $v_{23}$ & $G_{12}=G_{13}$ & $G_{23}$ & $\rho$ \\
\hline $127 \mathrm{GPa}$ & $9.1 \mathrm{GPa}$ & 0.31 & 0.45 & $5.6 \mathrm{GPa}$ & $4 \mathrm{GPa}$ & $1600 \mathrm{~kg} / \mathrm{m}^{3}$ \\
\hline
\end{tabular}


Table 2. Machining parameters used in drilling of T300/LTM45-EL laminate

\begin{tabular}{|c|c|}
\hline Drilling parameter & Magnitude \\
\hline Spindle speed (rpm) & 2500 \\
\hline Feed rate $(\mathrm{mm} / \mathrm{rev})$ & $0.06,0.12,0.20$ \\
\hline Feed rate,$f(\mathrm{~mm} / \mathrm{min})$ & $150,300,500$ \\
\hline Drill diameter (mm) & 3 \\
\hline
\end{tabular}

Table 3. Results for thrust force and torque at constant spindle speed of $2500 \mathrm{rpm}$

\begin{tabular}{ccc}
\hline Feed rate $(\mathrm{mm} / \mathrm{min})$ & Average thrust force $(\mathrm{N})$ & Average torque $(\mathrm{N}-\mathrm{cm})$ \\
\hline 150 & $114.4 \pm 0.5$ & $67.2 \pm 7.4$ \\
300 & $172.5 \pm 3.3$ & $103.1 \pm 10.6$ \\
500 & $202.1 \pm 4.1$ & $158.8 \pm 10.2$ \\
\hline
\end{tabular}


Table 4. Micro CT scanning parameters

\begin{tabular}{cc}
\hline Parameter & Magnitude \\
\hline Voltage $(\mathrm{kV})$ & 85 \\
Current $(\mathrm{mA})$ & 75 \\
Exposure time per projection $(\mathrm{s})$ & 2.34 \\
Total number of projections & 64 \\
Voxel size $\left(\mu \mathrm{m}^{3}\right)$ & $1375 \times 1649 \times 275$ \\
\hline
\end{tabular}

Table 5. Strengths properties of carbon/epoxy unidirectional laminate

\begin{tabular}{lc}
\hline Tensile strength in longitudinal direction $\left(X_{1 t}\right)$ & $2720 \mathrm{MPa}$ \\
Tensile strength in transverse direction $\left(X_{2 t}\right)$ & $111 \mathrm{MPa}$ \\
Compressive strength in longitudinal direction $\left(X_{1 c}\right)$ & $1690 \mathrm{MPa}$ \\
Compressive strength in longitudinal direction $\left(X_{2 c}\right)$ & $214 \mathrm{MPa}$ \\
Shear strength in longitudinal direction $\left(S_{12}\right)$ & $115 \mathrm{MPa}$ \\
\hline
\end{tabular}


Table 6. Material parameters used to model interface cohesive elements

\begin{tabular}{ccccccc}
\hline$K_{n}$ & $K_{s}=K_{t}$ & $G_{n}$ & $G_{s}=G_{t}$ & $t_{n}^{0}$ & $t_{s}^{0}=t_{t}^{0}$ & $\beta$ \\
$\left(\mathrm{N} / \mathrm{mm}^{3}\right)$ & $\left(\mathrm{N} / \mathrm{mm}^{3}\right)$ & $(\mathrm{N} / \mathrm{mm})$ & $(\mathrm{N} / \mathrm{mm})$ & $(\mathrm{MPa})$ & $(\mathrm{MPa})$ & \\
\hline $4 \times 10^{6}$ & $1 \times 10^{6}$ & 0.2 & 1 & 60 & 90 & 1.0 \\
\hline
\end{tabular}

Table 7. Delamination factors at drill entry and exit

Drill feed rate

$(\mathrm{mm} / \mathrm{min})$

Digital image processing technique

Drill entry

Drill exit

0.1396

0.2302

0.3409
Approx. delamination factor

(FE analysis)

\begin{tabular}{ccccc}
\hline 150 & 0.0294 & 0.1396 & 0.031 & 0.20 \\
300 & 0.0377 & 0.2302 & 0.039 & 0.34 \\
500 & 0.0379 & 0.3409 & 0.04 & 0.52 \\
\hline
\end{tabular}


Table 8. Drilling parameters chosen for optimisation study 